\title{
Articulating addiction in alcohol and other drug policy: A multiverse of habits
}

\section{ABSTRACT}

Concepts of addiction differ across time and place. This article is based on an international research project currently exploring this variation and change in concepts of addiction, in particular in the field of alcohol and other drug (AOD) use. Taking AOD policy in Australia and Canada as its empirical focus, and in-depth interviews with policy makers, service providers and advocates in each country as its key method $(\mathrm{N}=60)$, the article compares the addiction concepts articulated by professionals working in each setting. Drawing on Bruno Latour's theoretical work on the body and his proposal for a better science based on the 'articulation of differences', it explores the accounts of addiction offered across the Australian and Canadian project sites, identifying a shared dynamic in all: the juggling of difference and unity in discussions of the nature of addiction, its composite parts and how best to respond to it. The article maps two simultaneous trajectories in the data - one moving towards difference in participants' insistence on the multitude and diversity of factors that make up addiction problems and solutions, and the other towards unity in their tendency to return to narrow disease models of addiction in uncomfortable, sometimes dissonant, strategic choices. As I will argue, the AOD professionals interviewed for my project operate in two modes treated as distinct in Latour's proposal: in turning to reifying disease labels of addiction they take for granted, and work within, a 'universe of essences', but in articulating the multiplicity and diversity of addiction, they grope towards a vision of a 'multiverse of habits'. The article concludes by addressing this tension directly, scrutinising its practical implications for the development of policy and delivery of services in the future, asking how new thinking, and therefore new opportunities, might be allowed to emerge.

\section{Acknowledgments}

The research reported in this article was funded by an Australian Research Council Future Fellowship (FT120100215). I wish to express my gratitude to the BC Centre for Excellence in HIV/AIDS, which hosted a research visit for the project in 2014. I also thank Kate Seear and Jeanne Ellard for conducting some of the interviews analysed here, as well as the research participants, who were so generous with their time and insights. The National Drug Research Institute at Curtin University is supported by funding from the Australian Government under the Substance Misuse Prevention and Service Improvement Grants Fund. 


\section{Articulating addiction in alcohol and other drug policy: A multiverse of habits}

It has been observed many times that the concept of addiction is an effect of its times, that it emerged alongside Western Enlightenment notions of rationality and autonomy. If we did not value reason and autonomy so highly, if we did not have faith in the possibility of our rationality and independence, we would not so strongly fear a state defined as the opposite of these things - as irrational and dependent (Sedgwick, 1993; Fraser, Moore and Keane, 2014). In this sense addiction and modern society have made each other, even as each undergoes change. This article is based on a research project aimed at exploring the concept of addiction and its variations and changes, in particular in the area of alcohol and other drug (AOD) use. The arms of the project reported on here focus on AOD policy and service provision in Australia (two states: New South Wales and Victoria) and Canada (one province: British Columbia). Data collected in these sites comprises interviews with policy makers, advocates and service providers in each country, and focuses on questions about the addiction concepts at play in their work. Drawing on Bruno Latour's theoretical work on the body and his proposal for a better science based on the 'articulation of differences' (2004a), the article explores the accounts of addiction offered across the two project sites, identifying a shared dynamic in both: the juggling of difference and unity in discussions of the nature of addiction, its composite parts and how best to respond to it. In doing so, the article maps two simultaneous trajectories in the data - one moving towards difference in participants' insistence on the multitude and diversity of factors that make up addiction problems, and the other towards unity in their tendency to return to narrow disease models of addiction in uncomfortable, sometimes dissonant, strategic choices. As I will argue, the AOD professionals interviewed for my study operate on two planes treated as distinct in Latour's proposal: in turning to reifying disease labels of addiction they take for granted and work within a 'universe of essences', but in articulating the multiplicity and diversity of addiction, they grope towards a vision of a 'multiverse of habits'. The article closes by speculating on measures through which this paradox may be addressed such that more effective responses to drug use can be identified and implemented.

\section{BACKGROUND}

In Australia as elsewhere, alcohol and other drug consumption is understood to be the origin of a range of serious health and social problems. Governments have responded to this 
formulation of the place of AOD use in societal ills by devising a wide range of prevention, education and treatment measures, all of which are the subject of intense scrutiny and controversy. This article will focus on perhaps the most contested of all concepts at work in Australia's state response to AOD use, namely 'addiction'1, seeking to illuminate these concepts by examining Australian understandings alongside those found in another national setting, Canada. The research is based in a body of critical scholarship that has traced the historical development of notions of addiction in the West. According to Redfield and Brodie (2002: 2), who draw on the earlier work of Robin Room (e.g. 1983, 2003) and others, regular heavy drinking is a key starting point for tracking addiction concepts. They note that heavy drinking went un-labelled as 'addiction' for centuries prior to the emergence in the late $18^{\text {th }}$ and early $19^{\text {th }}$ centuries of the necessary political conditions for the generation of the label. After 'alcoholism' or alcohol addiction were identified, opium use also began to be framed in terms of addiction. This relatively short history is also reflected in the legal treatment of drugs. Not until the 20th century were any drugs criminalised in the US, Great Britain and Australia. This criminalising reflex can be seen as developing out of two key conceptual sources: 1) powerful typologies of deviance generated by the emerging post-Enlightenment disciplinary society (and the associated rise of the 'psy' disciplines such as psychoanalysis and psychology), and 2) the simultaneously emerging ethos of consumption (Redfield and Brodie, 2002, Room, 2003, Fraser, Moore and Keane, 2014). This confluence of pathologising categories and expanding consumption provided a rich basis for the rise of notions of pathological consumption or addiction. Indeed, the $20^{\text {th }}$ century not only embraced the idea of addiction: it produced it in myriad forms (Sedgwick, 1993). This context of addiction rarely surfaces in contemporary policy and practice debates on drug use and

\footnotetext{
${ }^{1}$ Heavy regular drug use is often problematised and given a label. The most widespread label in the Anglophone world is 'addiction'. This is a popular term as well as a specialist one - it has both technical and everyday currency. In Australia and in some other countries, health specialists and medical practitioners often prefer the term 'dependence', arguing that its medical cast is less stigmatising than addiction. In the US, addiction is more widely used and is the term of choice for the influential National Institute of Drug Abuse. The study on which this paper is based uses the broader term addiction as it is concerned not only with the medical or public health concepts but with the broader circulation of ideas and values associated with it. In this article my focus is mainly on questions about the phenomenon to which both terms refer. Does it exist? What is it? How should we respond to it? While some participants explain they prefer one term or another, it is always clear in the interviews that we are discussing the same phenomenon, and that, aside from one or two references to the narrower concept of 'physical dependence', the difference between the two labels relates to the politics of their reception rather than to the object to which they refer. In this article I use 'addiction' due to its broader salience.
} 
addiction. Yet assumptions about the nature of addiction saturate this debate, often helping to produce the very stigma and disadvantage AOD policy and practice aim to address (Fraser and valentine, 2008).

In keeping with the observation that addiction is socially and historically specific, this article explores two different national contexts: Australia and Canada. Both countries were early adopters of harm reduction (Ritter and Cameron 2006), and both are regularly ranked highly in overall standard of living (Tiffen and Gittens, 2004; Harchaoui and Tarkhani, 2003) while sustaining significant pockets of marginalisation and disadvantage in relation to drug use (Pennington, 2010; Ritter, Lancaster, Grech and Reuter, 2011). The similarities between the two nations suggest they have a lot to learn from each other, yet AOD-related research collaboration and exchange of information and best practice activity is extremely limited. The differences between the two countries - for example Canada's bilingualism, its much higher estimated rate of HIV among people who inject drugs (Ritter et al. 2011: 26), its shared border with the US, and each nation's different engagements with their indigenous populations and the AOD issues found in indigenous communities (Gray and Saggers, 2009) - also offer important opportunities for learning and exchange. For example, Sydney and Vancouver both host supervised injecting facilities which emerged out of extended, at times bitter, processes of political contestation (van Beek et al., 2004; Strathdee, et al., 1997; Rance and Fraser, 2011; Yamey, 2000; Gandey, 2003), but manage and respond to public scrutiny differently. These differences reflect different contexts in which addiction is understood, and suggest different responses to ideas of addiction (Tempier et al. 2009). To date no literature has been produced that could illuminate these differences, or the similarities the two countries share, and the opportunities they offer to the AOD field (Kimber, Dolan et al., 2003).

In keeping with these broad dynamics, Australia's and Canada's national drug policy documents also show similarities and differences. This article cannot undertake a comprehensive comparative analysis of these documents (some analysis of the Australian policy can be found in Moore, Fraser, Törrönen and Eriksson Tinghög, 2015), or of the various policies in place at state and province level in each country, but a few key observations are worth making about the two national strategies as they offer insights into the concepts, practices and structures relating to drug use and addiction at work in each country. It is notable that the current Australian National Drug Strategy (2010-2015) takes a relatively broad approach to its subject in that it includes tobacco and alcohol in its remit. Doing so is significant because it signals a certain liberal inflection in that it presents the consumption of drugs currently stigmatised as scandalous or shameful (ie. illicit drugs such 
as heroin or methamphetamine) as profitably discussed alongside the consumption of drugs currently treated as normal (ie. alcohol). Also, the Australian document adopts the language of dependence rather than addiction, signaling, at least in Australian discourse, a medical approach and the implicit goal of reducing stigma around drug use. The Canadian document differs from the Australian in immediately obvious ways: entitled The National Anti-Drug Strategy (2007), it articulates an overtly normative position on drug use from the outset and, indeed, it aims only to cover illicit drug use. Its language is that of addiction and dependence, however, and overall the document, ratified after what Wodak (2008) has identified as a conservative turn in Canadian drug policy, strikes neither a consistently liberal approach nor a consistently conservative one. In both documents, however, irrespective of terminology, and bearing in mind that both also canvass a range of other important AODrelated issues (binge drinking, child welfare, drink driving and so on), addiction presents as a stable, unified object, able to cause other problems (such as to 'motivate' crime, in Canada) and demand responses (notably 'recovery', in Australia).

\section{LITERATURE REVIEW}

While little comparative AOD research has been conducted on Australia and Canada, a significant body of work explores AOD policymaking in each country separately. The literature closest in focus to my work here is qualitative in approach, and covers several areas. Looking first at the Australian literature, some explores the role of research or evidence in the making of particular AOD policies and policy in general (Loxley, 2005; Hall, 2008; Spooner, 2009; Ritter, 2011; Ritter and Lancaster, 2013a; 2013b; Stevens and Ritter, 2013). In this literature questions are posed about: the assumptions researchers make about how policy is developed; and the strategic dimensions of evidence uptake, among others. A second group of Australian works looks explicitly at how AOD policy is developed and how it operates. In some of these works policy is essentially treated as a response to a pre-existing social or other problem (e.g. Ritter and Bammer, 2010; Ritter, 2010). In other Australian works, a 'constructivist' approach is taken in which policy is reframed to acknowledge its role in posing or constructing problems in particular ways according to specific political climates and the measures thought to be available within them (e.g. Fraser and Moore, 2011; Lancaster, 2014; Lancaster and Ritter, 2014; Bacchi, 2015). Another group of Australian works explores the particular assumptions informing policy, raising questions about the place in policy of phenomena such as pleasure (Moore, 2008; Keane, 2009), evidence (valentine, 2009) and care (Duff, 2015). Lastly, Australian research has also been published on the question of access to the policymaking process for affected communities (Lancaster, Ritter and Sutherland, 2013) as well as the place of personal experience in forming opinion on AOD policy (Lancaster et al., 2014). While these literatures shed much needed light on the 
processes in which policy is made, the unexamined assumptions that can limit policy, and the value of inclusiveness, they say relatively little about those tasked with developing and implementing AOD policy. Similarly, the Canadian literature does not address this question. It explores some of the same issues and processes examined in the Australian work, most obviously the role of research in policymaking (e.g. Reimer, Sawka and James, 2005; McCann, 2011; Stockwell et al., 2012), and how policies have been developed, here either by focusing on policy development processes (MacPherson, Mulla and Richardson, 2006; McCann, 2008; McCann, 2011; Watson, 2014) or by looking at policies historically (Quirion, 2003; Roe, 2005). Some work criticises particular policy developments in Canada, such as the shift towards the US 'War on Drugs' model (Wodak, 2008; Khenti, 2014) and some work considers how new, more desirable policies such as those supporting needle and syringe programs, harm reduction in prisons or medical marijuana, can be developed and implemented (Strike, Myers and Milson, 2004; Rehman et al., 2005; Fischer, Kuganesan and Room, 2015). As in the Australian context, some literature also exists on questions to do with consumers or affected communities and their relationship to policymaking and implementation (Kerr et al., 2006; Macdonald, Stockwell and Luo, 2010).

Overall, this Australian and Canadian work provides important context for the interviews analysed here, highlighting as it does the role of the media and other forces in shaping policy, the weaknesses in existing policies and the opportunities for improvements in policy. Adding to this work, this article aims to illuminate an aspect of policy development heretofore ignored - the understandings and assumptions of those working directly in policy development and in the realisation of policies in practice. As will become clear, many study participants, including career service providers and policymakers, articulate views noticeably remote from the policies on which their work is, at least in a broad sense, based.

\section{APPROACH}

In analysing the data collected for the project on which this article is based I adopt a Science and Technology Studies (STS) approach. My aim in using this approach is to illuminate a significant tension identifiable in the data (one at times openly lamented by participants), that is, the tension between treating addiction as fixed material/biological object and treating it as an emergent conceptual/political phenomenon. As I have argued elsewhere (Fraser, 2015; Fraser, Moore and Keane, 2014) STS offers valuable tools for resisting the ever-present tendency (lately in connection with neuroscience) to treat addiction as a fundamentally biological 'fact' able to straightforwardly determine policy and practice responses, while also avoiding treating addiction as merely 'constructed' in any simplistic sense - as purely the product of politics. Given AOD policy and practice are just as able to reproduce the problems 
associated with addiction as they are to fix them (Fraser and valentine, 2008), an urgent need exists to understand the phenomenon as irreducibly material and political. Bruno Latour's work is especially useful for this purpose. For Latour (2004), modern Western societies are characterised by a particular habit of thought. This habit of thought treats issues as constituted from incontrovertible stable facts based in a commonsense material world that need only to be discovered and understood by objective science. He advocates instead a habit of thought that sees issues as no less factual states of affairs, but always made in, and only discoverable through, the irreducible relationships between science, politics and matter. This is a shift from what he calls a focus on 'matters of fact' to a focus on 'matters of concern'. As he explains, 'Matters of fact are only very partial....and very polemical, very political, renderings of matters of concern' (2004b: 232) (see Fraser, 2011 for a detailed exegesis of this work). Latour's intention in this discussion is to expand understandings of phenomena so that they are seen as intrinsically political, built from continuous 'dealing and dispute', and not only as unproblematically objective, material and concrete. The role of science, including social science, he argues, is to develop new ways of addressing 'matters of concern' rather than trying to creating additional, or less contested, 'matters of fact'.

This way of thinking offers valuable tools for analysing addiction: as a matter of concern rather than a matter of fact. The idea, however, belongs to a larger conceptual framework. Matters of concern belong in a specific context: what Latour elsewhere calls the 'multiverse of habits'. In a second article published in 2004, he argues that we should not think in conventional terms of what he calls a 'universe made of essences' (the kind of universe made up of stable matters of fact), but in a very different mode; that of a 'multiverse made of habits' (2004b, 213). Here he defines multiverse as a way of conceiving the universe 'freed from its premature unification' (213). This is a universe in which it is 'habit' that holds phenomena stable, making realities through repetitive practices. What is habit in this formulation? I interpret the word here to mean intentional and unintentional enactments, but enactments understood outside the binary framework commonly taken to characterise reality: binaries of discourse and matter, free will and compulsion and so on (for more on habit see Latour, 2004a, 2004b; and Fraser, Moore and Keane, 2014). This formulation of the multiverse and its constitution in habit is part of a larger argument Latour makes, following Isabelle Stengers, proposing a new standard for science. Good science, they both argue, is not reductive. It articulates differences instead of fixing facts. By this they mean that good science avoids narrow models of proof and falsifiability. Instead it aims to build more differences onto those already known, making clearer the distinctions between phenomena instead of reducing these phenomena to generalisations of the same, eliminating alternative 
versions and seeking to discount them via an authoritative claim to a single truth. If scientists do science in the way he proposes, Latour argues, the result will not be, as some might fear, multiple worlds with no hope of resolution, but the multiverse, a universe of complexity, instability, difference and nuance, one that recognises that ways of knowing make the realities they seek to know, and thus that realities are necessarily multiple. Unlike the universe of essences, this multiverse is not 'done on the cheap and without due process' (2004b, 213). In this way, he argues, we can engage in the continuing task of 'composing the common world' (2004b, 222), creating a society, laws, policies and institutions, in a more ethical and effective manner.

This article is an attempt to initiate research of this kind. To relate these observations to my own project, I must, it seems, think about the knowledge I make (here about the knowledgemaking of others) as forming part of the task of composing the common world (2004b, 222). I must avoid the trap that the sciences of addiction - neuroscience, DSM-based psychiatry and psychology and so on - seem to fall into over and over in debating and laying claim to addiction; that of seeking to compose once and for all and right now a 'common world' of addiction so that we can all work together with the same tools for its eradication. Instead, Latour says, using Stengers' word, the sciences must be more 'polite' when entering explanations into the 'composition of the common world':

No common world can be achieved if what is common has already been decided, by the scientists, out of sight of those whose 'commonalities' are thus made up.

In reading Latour's work I am taken with his recognition of the importance of other enduring versions of reality and the need to leave room for more than the versions conventional sciences are equipped and inclined to produce. In the book, Habits: Remaking addiction (2014), David Moore, Helen Keane and I introduce these ideas, using a wide range of data including interviews with many different groups to demonstrate the need to attend to the many enduring differences of addiction. In this article I take a further step, pointing to a tension at the centre of new material collected from professionals tasked with producing and implementing AOD policy, that is, a simultaneous scepticism about the unitary notion of addiction and a perceived need (for some as a strategic move) to mobilise it nonetheless.

There is no doubt that conventional scientific method and the processes of fact-making it engages in have come under sustained attack over the last few decades, accompanied by a popular groundswell of scepticism about scientific infallibility. Latour cites climate-change scepticism as an exemplar of this, but a range of important examples have been identified over the last decade (see, for instance, Irwin and Michael 2003 for a discussion of these 
issues). In proposing the undoubtedly significant shift in thought he does, however, Latour is not insensitive to the scale of his ambition. While some might object that such ambition is impractical - that shifting scientific thought and practice in this way is more than unlikely - it is important to recalled that major shifts in thinking do occur, as exemplified in the rise of poststructuralism and its impact on the humanities and social sciences, and in turn on public debate, since its emergence in the 1970s and 1980s. This article is in one sense an attempt to document the basis on which such a shift might come to be considered worthwhile and necessary in relation to addiction, and to place into academic debate a call to consider the implications of undertaking such a shift for AOD policy and service provision.

In the sections that follow I present material from the interviews conducted for my study, read in light of Latour's insights. The material is presented in three sections, the first two of which reflect an extremely pronounced theme in the interviews - the elusiveness, complexity and ineffability of addiction, what we might describe as its weak performance in any universe of essences - while the third covers a related theme - the need to speak of addiction, to partake of the universe of essences, anyway. In conducting this discussion I aim for a double analytical process: first I lay the ground for a discussion that does as Latour and Stengers advocate - articulate differences and use these to intervene in the common world currently undergoing composition in relation to addiction - but also I identify a dual action in the data itself, one that moves simultaneously towards differences and matters of concern and back to essences and matters of fact. I ask why this dual action occurs and speculate on our shared responsibility for the common world that reflects and constitutes these ideas.

\section{METHOD}

The analysis is based on 60 qualitative interviews conducted with AOD policymakers and service providers collected in two national sites: Australia - Victoria $(n=20)$ and New South Wales $(n=20)$ - and British Columbia, Canada $(n=20)$. The interviews were collected in three phases, the first, Victoria, as a pilot study in 2011 and the second and third, NSW and BC, in 2014. In each site a variety of professionals working in the AOD field (government and nongovernment policy makers, senior service providers in harm reduction and treatment services, and representatives of advocacy groups) were interviewed. Prospective participants were identified by consultation with key informants in each setting. Those identified were then approached by email: information about the project was supplied and all subsequent volunteers (the majority of those approached) were then interviewed. Organisations participating in the data set include state or province health and social welfare government departments, non-government organisations delivering advocacy and policy advice and prevention programs, treatment clinics, primary healthcare providers and drug 
consumption rooms. Participants ranged from senior government policymakers and department heads, NGO-based managers, advocates, psychologists, pharmacotherapy prescribers, counsellors, peer representatives and pharmacists.

The interviews used an open-ended interview schedule in which participants were asked about the nature of their work, the issues they deal with in their day-to-day activities, their understanding of key concepts in the field such as addiction, recovery, and the approaches, tools and models they rely upon as well as those they consider unhelpful. The interviews were on average approximately an hour in duration and were transcribed and coded thematically using NVivo. These themes were identified using a combination of methods: some themes arose from the literature and the questions it poses about concepts of addiction and how they are mobilised, and some were derived from the interviews themselves.

The project was granted ethics approval by the Curtin University Human Research Ethics Committee (\#HREC 37/2013).

\section{ANALYSIS: 'Simple answers, wouldn't that be great!'}

In the sections below I present two opposing but related accounts of addiction identified in the interviews. In the first two sections are accounts that in different ways articulate addiction as what Latour might call a 'matter of concern', that is, in terms so multiple and complex, so marked by contestation and uncertainty, that important questions arise about the coherence of the concept and the extent to which it can be defended. The third section demonstrates a contrary dynamic, the mobilisation of addiction very much as a stable matter of fact, and attempts to shed light on why these apparently contrary accounts of addiction also claim a significant place in discourses of addiction.

\section{Articulating differences}

By far the most widely articulated characterisation of addiction given in all three interview sites is one that incorporates a wide range of factors into its explanation of the causes of addiction and its vision of how addiction should be tackled. In the two Australian sites a common response to questions about the causes and nature of addiction is to describe it as a 'bio-psycho-social problem' or a 'multifactorial' one, while in British Columbia, the politics of colonisation and related moves to recognise indigenous spirituality have seen the former term made even more expansive: 'bio-psycho-social-spiritual'. According to one of our Victorian participants (James, service provision), addiction is a comprehensive affliction affecting all aspects of the self: 
Put all that together and you get a desperate downward spiral which is both biopsycho-social. So [the affected individual] basically disintegrates as a personality, as a social being and as a functioning cognitive being. So our model is highly eclectic... NSW participant Cameron (service management) offers a similarly expansive account of addiction and how to understand it. According to him, narrow approaches, exemplified in the neuroscientific 'brain disease' approach, can be useful, but also needed are:

a sociological analysis, a legal analysis, a social justice analysis, you know, sometimes cultural issues, all of the things that come into play in people. [We also need a] gender analysis, you know... if there's too much emphasis on addiction as a brain disease, that's problematic.

Also speaking about the place of neuroscience in addiction treatment, a participant from the $\mathrm{BC}$ arm of the study, Sean (service provision), makes a similar point about the many factors that cause and can help overcome addiction:

I think it's maybe part of it but I think there are other factors, other components there. I think it's fairly limiting to just describe it as disease because it discounts other important factors around the person, around the psychological aspects that enter into the realm of the social context or cultural context or the spiritual piece...

Perhaps the most vivid articulation of this commonly used multifactorial approach to addiction comes from Jess (BC, government policy). Drawing on an idea she encountered in a TED talk given by a neuroscientist, Jess describes the context of addiction as a 'connectome', a term used by the neuroscientist to acknowledge the sobering complexity of the brain and the difficulties scientists face in mobilising ideas about the brain to produce effective treatments for issues such as addiction. As she explains,

So the 'connectome' is analogous to the genome. So you can talk about genes but your genome is the whole genetic makeup... the connectome is the full weight of the connections of your neural circuitry and the feedback from your body and all that kind of stuff. And there are people trying to map that, and those guys, I love those guys because they say, 'Not in my lifetime'.

Elaborating the connectome idea further, Jess explains that the author of the term rejects genetic explanations as simplistic. She paraphrases him as follows:

He says, 'A lot of people say you are your genome. I don't think so because your genome is set when you're born but it's incredibly influenced and right to the day you die, how your genes express themselves at any given moment is in relationship to your environment; stress, heat, all kinds of diet, all of these kinds of things'. This comprehensive set of relationships between brain structure and environment is the connectome. According to Jess, any approach that simplifies this too far, such as narrow 
brain disease models of addiction, are obviously flawed. As Jess puts it, 'intuitively, I think that's BS.' Nicole, a Victorian participant, makes this point especially clearly, focusing on what is at risk of erasure when the language of addiction is adopted:

For me, once we start using terminology like that we start looking at that manifestation of the problem, as in addiction, rather than the broad range of things either that have lead the person there, which you may not have much control over now, or, how the various ways that's been manifested... I think in many ... or the people we see there's other issues that have been there you know, in terms of they've been through child protection system, they've been through justice, they've been in prison, they might've had sexual abuse, there's a range of things. So therefore, to go 'this person's an addict or got an addiction', my concern is [first that]... we're not quite clear that addictions exist in the sense. But, my concern about naming and framing something like that is that some of the other stuff then seems to drop away from our consciousness, in terms of how we respond to the person.

In presenting these extracts here my aim is to indicate the depth and breadth of the participants' rejection of narrow accounts of addiction, and the strength of their inclination to see addiction as caused by, and most effectively confronted through, a combination of many different elements. In Latour's terms, these addiction professionals generate many, many 'differences' of addiction. They see it as an effect of many different forces and objects, manifest in many different ways, producing many different experiences, and in need of many different responses. For the purposes of the argument I make here, this material can be read as a challenge to the unity and clarity of the addiction concept itself. Addiction is best characterised here as a matter of concern. It cannot, in other words, be reduced to a narrow matter of fact, with a narrow causal frame and clear, predictable responses. Attempting to do so, perhaps through the overly confident pronouncements of neuroscience, sees it reified into an unrecognisable and practically unhelpful object. Thus, for Stewart (Vic, service provision), addiction is nothing but an 'umbrella' term. For Hugh (NSW, service provision), it is 'too baffling for...a uniform conception'. And for Ruby (BC, advocacy) it is merely a 'signal amplifying term' that creates a sense of coherent meaning where there is none.

\section{Diagnosing 'self-medication'}

Even where addiction is discussed in more concrete terms and its existence treated as uncontroversial, key terms with which it is formulated again raise fundamental questions about its coherence. Common across all three sites are formulations of the causes and substance of addiction that prioritise the role of trauma, psychic pain and the notion of 'self- 
medication'. These ideas warrant close scrutiny, especially in relation to what they imply about how the category of addiction is constituted. According to Eileen (BC, government policy), emotional trauma or pain is a key cause of addiction. As do other participants in the $\mathrm{BC}$ arm of the study, she cites the impact of colonisation and the trauma of dispossession experienced by indigenous Canadians:

The biggest problems that we see locally amongst our addictions population, and I think probably internationally, are trauma related, the history of Aboriginal people in this country and their residential schools and the colonisation and the cultural genocide that's occurred here - the effects are still very strong.

Janine (research, service policy design), also in the BC arm of the study, focuses her attention on gender-based trauma as a cause of addiction:

I realised the overwhelming number of women had backgrounds of physical, sexual and emotional abuse, and that is often an underlying reason. You can't take away what's helping them deal with that pain without helping them work through what's gotten there in the first place. That's a whole other exploration that needs to happen for them.

Formulations that treat addiction as the result of individual attempts to cope with psychic pain and trauma are also found in the New South Wales and Victorian data (although a notable difference is the silence among Australian participants about colonial trauma). As Elizabeth (NSW, service provision) explains:

Obviously there's this sub-population who are probably not necessarily representative of the whole but they are the people that in the community [...] who have often got very significant traumatic backgrounds, who are in a, sort of, suspended in post-traumatic stress syndrome-type situation and who have often left school and home around 14, started injecting, started sex working very young and who have a lot to forget, for whom their drug use is for somewhat self-medicating [...] sort of numbing stuff from the past and from the present.

Kevin (NSW, non-government policy and service provision) also makes these connections, but his way of formulating the problem is especially striking for questions about the basis of addiction:

[For] those people that have their lives so adversely affected by trauma or abuse or just having a terrible life, then without actually dealing with the terrible-life syndrome [you are] wasting your time thinking they are going to get any better. You've got to deal with the terrible-life syndrome as well as everything else. 
Here Kevin treats addiction as the symptom of a different disease - 'terrible-life syndrome' made up of negative life experiences and poor social conditions. Nicole (Vic, service provision) makes a similar point, adding further complexity to Kevin's view by emphasising that experiences of trauma, abuse and neglect can play out in different kinds of addiction:

All of this early life stuff or whatever you want to call it, abuse and neglect, trauma, whatever else, plays out in different people in different ways. Now, you know, for one person maybe it plays out in the alcohol and drug way, for some other person it might be around food and that. So I think if you look kind of deep in the person, in the psyche, there might be similar things happening.

In these extracts can be found an approach to addiction that simultaneously articulates it as a real unified disease or problem while diagnosing other aspects of life and the self as the primary underlying condition that causes it. The implications for policy of this seemingly contradictory combination of ideas remain, I suggest, to be thoroughly interrogated. If the causes of addiction lie in trauma, psychic pain, poor social conditions and a need for selfmedication, addiction can be considered an effect of other, more fundamental, ills. This interpretation entails questions about the extent to which addiction can be treated effectively as a disease in itself, especially in relation to the idea of self-medication, which has generated a large clinical literature but little careful critical attention. The suggestion behind this idea is that various forms of dis-ease lead individuals to attempt their own treatment through the consumption of (often ineffective or actively harmful) lay 'medications'. Addiction, in this approach, could be considered a catch-all 'disease of wrong medication'. Clearly this is a rather vague and weak basis on which to rest a disease concept, even if its intention is a sympathetic and compassionate one, as is often argued (see, for example, Khantzian and Albanese, 2008: XV). Of course, for all those who resist the idea that their drug use, even if regular or what they or others call addiction, is a pathological phenomenon - something that signals or manifests their psychic disease - it can be even less persuasive.

In short, while the first section of this data analysis identified explicit statements articulating the complexity, elusiveness and artificiality of the addiction concept, this second section identifies a key implicit way this multiplicity strains to cohere. Here we see the many differences identified by the interview participants organised into a diagnosis aiming for stability and unity. Why does this process of organisation and diagnosis continue to occur given so many professionals articulate little faith in such diagnoses? In the next section we will see that although participants describe addiction as bafflingly complex, an effect of a dizzying range of factors too complex to capture, many also frame it as a coherent and unitary disease nonetheless. 


\section{Rebuilding matters of fact}

The advent of neuroscientific accounts of addiction has given fresh impetus to the articulation of addiction as disease (Courtwright, 2010; Campbell, 2012; Fraser, Moore and Keane, 2014), and evidence of this development can be found in the interviews analysed here. Addiction is a highly complex phenomenon, nevertheless it seems many find value in balancing this complexity with cautious simplification. As Eileen (BC, government policy) explains:

We are developing a new disease-based model, you know, a brain-oriented medical model of addiction medicine, which I wholeheartedly support as long as it also includes an understanding of psychology and an understanding of the social determinants of it...

Eileen goes on to express doubts about the model even as she acknowledges its tactical value for aiding affected people:

I don't think [addiction is] a disease as such, I don't think you can catch it and I don't think it's something that's sort of develops like diabetes or something like that. I know those models are used to try and help people, but I just don't think it's accurate.

[Emphasis added]

Francesca (NSW, non-government policy) also offers an overview of the uptake of disease language, noting that it enjoys quite variable acceptance but is aimed at producing beneficial change:

there's lots of sensitivity around language we use in the sector and how it's defined. Some people refer to it as a disease, some people don't so, you know, I guess in the end, however or whatever you call it and however you define it, is that they are trying change behaviour... [Emphasis added]

In both these cases the influence of disease models of addiction is acknowledged along with the therapeutic and strategic purposes for which they may be used. At the same time, reservations about disease models as limited and narrow are expressed.

Importantly, even those strongly critical of disease models find it difficult to abandon them altogether. Sean (BC, service delivery) illustrates this in his explanation of the merits of disease models, and specifically the new approaches based in neuroscience:

[A client] may feel like a weak or a bad person because of their cravings. We teach them 'actually this is what's happening in your brain, you're in withdrawal and your brain is craving these substances and that's why you feel this way'.

Here Sean endorses the brain disease model as useful for counteracting shame and the effects of stigma, but this does not mean he is unambivalent about it: 
I think it's fairly limiting to just describe it as disease because it discounts other important factors around the person, around the psychological aspects and enters into the realm of the social context or cultural context or the spiritual piece... Amanda (Vic, non-government policy, advocacy) too criticises the poverty of disease models, but identifies a different set of strategic dimensions in the terminology. First she explains her antipathy towards the idea of addiction as a disease:

I have young people doing speaker engagements, and a lot of them I get from the recovery support service. And they will speak about their disease and their recovery from their disease, and all those sort of terms [...] I can see them grappling with it as they're talking, because it is bullshit [laughs].

Next, Amanda goes on to explain the uses to which the disease model can be put (focusing on the common disease formulation in Australia of addiction as a 'chronic relapsing condition'):

I was in a forum [...] one day and there were some family members [asking], 'What do you do when someone's banging on the door and you can't let them in, and they're in a [drug] episode, blah, blah, blah, and we've got to call the police, rah, rah, rah.' And I'm saying, 'Well [...] it's a chronic relapsing condition.' I'll bring it out then. And it's the wrong thing, but I will bring out because it makes what I say more palatable.

For Amanda, disease models of addiction offer a very poor fit for individual experiences but cannot be abandoned altogether because they also offer one of very few ways of garnering understanding and sympathy for people who use drugs.

Common to these statements is a sense of the weakness of disease models even as they are considered important for effecting change in drug use, alleviating shame and stigma, and promoting acceptance. It seems that despite many expressions of resistance to simplistic reifying models of addiction, both explicit and implicit, professionals working in all kinds of roles in the field find abandoning them impractical and difficult to achieve. Viewed in Latourian terms, they find themselves consistently required to operate, however reluctantly, within the universe of essences (2004a).

\section{CONCLUSION}

To sum up, across all three sites the interviews suggest a strong sense of the strategic need to invoke disease models of addiction (and by implication, to reify and essentialise addiction as an independent, unified entity). At the same time, they articulate a very pronounced longing to respond to drug use in entirely different ways. While there are some important 
differences between sites, such as the sensitivity to colonialism and spirituality in BC participants' responses versus the silence on these issues in the Australian interviews, commonalities stand out. This paper has focused on one key commonality, the marked dissonance between perceptions of the true complexity and variability of experiences labelled addiction, and the strategic indispensability of the term and its stabilising tendencies. Whether addiction itself exists as a meaningful independent entity, whether it should be seen as a disease, what this term means and what to do with its stigmatising effects - these are not new questions, of course, nor is the recognition that disease concepts may at times be mobilised strategically to counter stigma or command resources (Carr, 2011; Moore and Fraser, 2013). The extent to which so many key participants in AOD policy making and service provision, speaking in two countries, criticise reifying and essentialising disease models and articulate perspectives that either explicitly or implicitly destabilise or even disavow them is, however, striking and deserving of attention. In particular, it raises important questions about the need to create change such that these anti-essentialist approaches, and the many 'differences' they promise to produce, can find better expression in policy and in the service provision that is inevitably shaped and delimited by policy. It also raises questions about the relationships that can be mapped between these two approaches to addiction. The data presented here have identified strategic factors at work in the transitions participants make between the two, although it is important to stress that the approaches are not equivalent in the data. Essentialist accounts are presented as strategically useful while anti-essentialist accounts are presented as the expression of a genuine conviction. Other studies could identify further factors in these transitions, especially where the research is based in different contexts, such as the media or youth drug prevention education. Such work would aid in clarifying how and why particular approaches arise in particular circumstances.

As has been argued elsewhere (Moore and Fraser, 2013), the way addiction is articulated can impact significantly on treatment policy, and on the shape of services and how they are delivered. Likewise, given subjective experiences of addiction are in part shaped by these institutional forces, changing them would in turn allow the emergence a broader range of accounts of regular drug use, broader subjective experiences of the issues currently gathered under the language of addiction and more cross-linking and accessing of services where needed (Pienaar, Fraser, Moore, Kokanovic and Treloar, 2015). It is difficult to escape the conclusion that among those at work in our governments and AOD services there is little faith in addiction as a unitary coherent phenomenon that can be readily addressed by dedicated narrowly conceived treatments, yet this idea continues to be promulgated because 
strategic alternatives are absent.

From where might these alternatives emerge? It seems a significant shift is needed, one that Latour has identified many times now in general terms $(2004,2013)$, and that would alter society and policy beyond one field alone. If we reformulate our world, and our view of it, as a 'multiverse of habits', we can perhaps remake policy (and its expression in services) in new more flexible, less essentialising ways. We can, perhaps, think in terms of the fluctuations and stabilisations of habit, rather than the irreversible rigidity of essence, asking what happens when we create addiction as a stable problem - when we take part in 'addicting' our world (Fraser, Moore and Keane, 2014) - and relegate the broader issues some people affected by it face to secondary or distal status. Certainly, the material collected for this project raises pressing questions about focusing policy and services on addiction (or even drug use) per se at all. As our interviews suggest, treating addiction as a matter of concern existing within a multiverse of habits means recalibrating our understanding of individual experience to include and integrate conventionally divided domains (including the history and politics of colonisation, family trauma, poverty and so on) but also, perhaps more challengingly, it means understanding addiction as fundamentally multiple and unbounded, and as such, not narrowly or exclusively negative (Pienaar et al., 2015). To do this, consideration might be given, for example, to Australia's current focus on drug use as a fundamental or foundational problem. While there is no doubt some drug use is associated with social and health problems, it is now well established in a range of research (from the early 'rat park' work of Alexander, 1978, to its uptake in the recent, widely embraced, popular science of Hart, 2013, to the more scholarly treatments by Duff, 2014, and others) that such problems are the effects of the confluence of challenges and issues, and that drugs on their own are not capable of wreaking the havoc so commonly ascribed to them. This means, inter alia, rethinking our rather narrowly framed national and state drug strategies, and asking whether Australia needs more thoroughly and overtly interlinked strategies on, for instance, related social issues of poverty, family violence, historical dispossession and homelessness. Likewise it means thinking drug use itself as a social issue, with all the messy overlapping complexity this entails, rather than, as is the case at present, a narrowly conceived health issue. As long as drug use is itself so heavily freighted with the causal responsibility for harm, and located within the potentially pathologising realm of health and disease, the strategic use of the essentialised category of 'addiction' will be a difficult habit to break. Indeed, in grappling with the task of 'composing a common world' through our policies, services and advocacy, we might begin with habit (Fraser, Moore and Keane, 2014): addiction as more flexibly understood as habit, transversely connected with other, sometimes productive, habits. Likewise, we might recognise addiction sciences, 
policies and treatments as habit too, and the possibility and necessity of forming new habits of thought and practice through and for better policy. 


\section{REFERENCES}

Alexander, B., Coambs, R \& Hadaway, P. (1978). The effect of housing and gender on morphine self-administration of rats. Psychopharmacology, 58(2), 175-179.

Bacchi, C. (2015). Problematizations in alcohol policy: WHO's 'alcohol problems'. Contemporary Drug Problems, 42(2), 130-147.

Carr, E. Summerson (2011). Scripting addiction: The politics of therapeutic talk and American sobriety. Princeton, NJ: Princeton University Press.

Campbell, N. (2012). Medicalization or biomedicalization: Does the diseasing of addiction fit the frame? In J. Netherland (Ed), Critical perspectives on addiction (pp. 3-25), New York: Emerald.

Courtwright, D. (2010). The NIDA brain disease paradigm: History, resistance and spinoffs. Biosocieties, 5(1), 136-147.

Government of Canada. (2012). National Anti-Drug Strategy. Accessed online 12/08/15 at: http://healthycanadians.gc.ca/anti-drug-antidrogue/index-eng.php

Duff, C. (2014). Assemblages of health. Dordrecht: Springer.

Duff, C. (2015). Governing drug use otherwise: For an ethics of care. Journal of Sociology, 51(1), 81-96.

Fischer, B., Kuganesan, S. \& Room, R. (2015). Medical Marijuana programs: Implications for cannabis control policy - observations from Canada. International Journal of Drug Policy, 26(1), 15-19.

Fraser, S. (2011). Beyond the 'potsherd': The role of injecting drug use-related stigma in shaping hepatitis C. In S. Fraser \& D. Moore (Eds), The drug effect: Health, crime and society. (pp. 91-105.) Melbourne: Cambridge University Press.

Fraser, S. (2015). A thousand contradictory ways: Addiction, neuroscience and expert autobiography. Contemporary Drug Problems, 42(1), 38-59.

Fraser, S. \& valentine, k. (2008). Substance and substitution: Methadone subjects in liberal societies. Basingstoke: Palgrave.

Fraser, S. \& Moore, D. (2011). The drug effect: Health, crime and society. Melbourne: Cambridge.

Fraser, S., Moore, D. \& Keane, H. (2014). Habits: Remaking addiction. Basingstoke: Palgrave.

Gandey, A. (2003). US slams Canada over Vancouver's new drug injection site. Canadian Medical Association Journal, 169(10), 1063.

Gray, D. \& Saggers, S. (2009). The evidence base for responding to substance misuse in Indigenous minority populations. In T. Stockwell, P. Gruenewald, J. Toumbourou \& W. Loxley (Eds), Preventing harmful substance use: The evidence base for policy and practice. Chichester, UK: John Wiley \& Sons. 
Hall, W. (2008). The contribution of research to the development of a national cannabis policy in Australia. Addiction, 103(5), 712-720.

Harchaoui, T., Jean, J. \& Tarkhani, F. (2003). Prosperity and productivity: A CanadaAustralia comparison. Economic Analysis Research Paper Series, Ottawa: Statistics Canada No. $11 \mathrm{~F} 0027$ No. 018.

Khenti, A. (2014). The Canadian war on drugs: Structural violence and unequal treatment of Black Canadians. International Journal of Drug Policy, 25(2), 190-195.

Keane, H. (2009). Intoxication, harm and pleasure: An analysis of the Australian National Alcohol Strategy, Critical Public Health, 19(2), 135-142.

Kerr, T., Small, W., Peeace, W., Douglas, D., Pierre, A. \& Wood, E. (2006). Harm reduction by a 'user-run' organization: A case study of the Vancouver Area Network of Drug Users (VANDU), International Journal of Drug Policy, 17(2), 61-69.

Khantzian, E. \& Albanese, M. (2008). Understanding addiction as self medication: Finding hope behind the pain. Rowman and Littlefield.

Kimber, J., Dolan, K., van Beek, I., Hedrich, D. \& Zurhold, H. (2003). Drug consumption facilities: An update since 2000. Drug and Alcohol Review, 22(2), 227-233.

Lancaster, K. (2014). Social construction and the evidence-based drug policy endeavor. International Journal of Drug Policy, 25(5), 948-951.

Lancaster, K., \& Ritter, A. (2014). Making change happen: A case study of the successful establishment of a peer-administered naloxone program in one Australian jurisdiction. International Journal of Drug Policy, 25(5), 985-991.

Lancaster, K. Sutherland, R. \& Ritter, A. (2014). Examining the opinions of people who use drugs towards drug policy in Australia. Drugs: Education, Prevention, and Policy, 21(2), 93101.

Lancaster, K., Santana, L., Madden, A. \& Ritter, A. (2014). Stigma and subjectivities: Examining the textured relationship between lived experience and opinions about drug policy among people who inject drugs. Drugs: Education, Prevention, and Policy, 22(3), 224-231.

Latour, B. (2004a). How to talk about the body? The normative dimension of science studies. Body \& Society, 10(2-3), 205-229.

Latour, B. (2004b). Why has critique run out of steam? From matters of fact to matters of concern. Critical Inquiry, 30, 225-248.

Latour, B. (2013). An inquiry into modes of existence: An anthropology of the moderns. Cambridge: Harvard University Press.

Loxely, W., Gray, D., Wilkinson, C., Chikritzhs, T., Midford, R. \& Moore, D. (2005). Alcohol policy and harm reduction in Australia. Drug \& Alcohol Review, 24(6), 559-568.

MacPherson, D. Mulla, Z. \& Richardson, L. (2006). The evolution of drug policy in Vancouver, Canada: Strategies for preventing harm from psychoactive substance use. International Journal of Drug Policy, 17(2), 127-132. 
Macdonald, S., Stockwell, T. \& Luo, J. (2010). The relationship between alcohol problems, perceived risks and attitudes toward alcohol policy in Canada. Drug \& Alcohol Review, 30(6), 652-658.

McCann, E. (2008). Expertise, truth, and urban policy mobilities: Global circuits of knowledge in the development of Vancouver, Canada's 'four pillar' drug strategy. Environment and Planning A, 40(4) 885-904

McCann, E. (2011). Points of reference: Knowledge of elsewhere in the politics of urban drug policy. In E. McCann and K. Ward (Eds) Mobile urbanism: Cities and policy-making in the global age (pp. 97-123). Minneapolis: University of Minnesota Press.

Ministerial Council on Drug Strategy. (2011). National drug strategy 2010-2015. Canberra: Commonwealth of Australia.

Moore, D. (2008). Erasing pleasure from public discourse on illicit drugs: on the creation and reproduction of an absence. International Journal of Drug Policy, 19(5), 353-358.

Moore, D. \& Fraser, S. (2013). Producing the 'problem' of addiction in drug treatment. Qualitative Health Research, 23(7), 916-923.

Moore, D., Fraser, S., Törrönen, J. \& Eriksson Tinghög, M. (2015). Sameness and difference: Metaphor and politics in the constitution of addiction, social exclusion and gender in Australian and Swedish drug policy. International Journal of Drug Policy, 26(4), 420-428.

Pennington, D. (2010). The politics of illicit drugs: The war on drugs can never succeed; Where should we go? Paper presented at The Australasian Professional Society on Alcohol and other Drugs Conference.

Pienaar, K., Fraser, S., Kokanovic, R., Moore, D., Treloar, C. \& Dunlop, A. (2015). New narratives, new selves: Complicating addiction in online alcohol and other drug resources. Addiction Research \& Theory (early online).

Quirion, B. (2003). From rehabilitation to risk management: the goals of methadone programmes in Canada. International Journal of Drug Policy, 14(3), 247-255.

Rance, J. \& Fraser, S. (2011). Accidental intimacy: Transformative emotion and the Sydney Medically Supervised Injecting Centre. Contemporary Drug Problems 38(1), 121-124.

Redfield, M. \& Brodie, J.F. (Eds.) (2002). High anxieties: Cultural studies in addiction. Berkeley: University of California Press.

Rehman, L., Gahagan, J., DiCenso, A. \& Dias, G. (2005). Harm reduction and women in the Canadian national prison system: Policy or practice? Women \& Health, 40(4), 57-73.

Reimer, C. Sawka, E. \& James, D. (2005). Improving research transfer in the addictions field: A perspective from Canada. Substance Use \& Misuse, 40(11), 1707-1720.

Roe, G. (2005). Harm reduction as paradigm: Is better than bad good enough? The origins of harm reduction. Critical Public Health, 13(3), 243-250.

Ritter, A. (2010). Illicit drugs policy through the lens of regulation. International Journal of Drug Policy, 21(4), 265-270. 
Ritter, A. (2011). The role of research evidence in drug policy development in Australia. Politicka Misao, 48(5), 141-156.

Ritter, A. \& Bammer, G. (2010). Models of policy-making and their relevance for drug research. Drug \& Alcohol Review, 29(4), 352-357.

Ritter, A. \& Cameron, J. (2006). A review of the efficacy and effectiveness of harm reduction strategies for alcohol, tobacco and illicit drugs. Drug \& Alcohol Review, 25(6), 611-624.

Ritter, A. \& Lancaster, K. (2013a). Measuring research influence on drug policy: A case example of two epidemiological monitoring systems. International Journal of Drug Policy, 24(1), 30-37.

Ritter, A. \& Lancaster, K. (2013b). Illicit drugs, policing and the evidence-based policy paradigm. Evidence \& Policy: A Journal of Research, Debate \& Practice. 9(4), 457-472.

Ritter, A., Lancaster, K., Grech, K. \& Reuter, P. (2011). Monograph No. 21: An assessment of illicit drug policy in Australia (1985-2010): Themes and trends. DPMP Monograph Series. Sydney: National Drug and Alcohol Research Centre.

Room, R. (1983). Sociological aspects of the disease concept of alcoholism. In R. Smart (Ed.), Research advances in alcohol and drug problems (pp. 47-91), London and New York: Plenum Press.

Room, R. (2003). The cultural framing of addiction. Janus Head, 6(2), 221-234.

Sedgwick, E. (1993). Epidemics of the Will, in her Tendencies. London: Routledge.

Strike, C., Myers, T. \& Milson, M. (2004). Finding a place for needle exchange programs. Critical Public Health, 41(3), 261-275.

Stockwell, T., Buxton, J., Duff, D., Marsh, D., MacDonald, S., Michelow, W., et al. (2009). The British Columbia Alcohol and other Drug Monitoring System: Overview and early progress. Contemporary Drug Problems, 36(3-4), 459-484.

Spooner, C. (2009). Social determinants of drug use - barriers to translating research into policy. Health Promotion Journal of Australia, 20(3), 180-185.

Stevens, A. \& Ritter, A. (2013). How can and do empirical studies influence drug policies? Narratives and complexity in the use of evidence in policy making. Drugs: Education, Prevention \& Policy, 20(3), 169-174.

Strathdee, S., Patrick, D., Currie, S., Cornelisse, P., Rekart, M., Montaner, J., et al. (1997). Needle exchange is not enough: Lessons from the Vancouver injecting drug use study. AIDS, 11(8), F59-F65.

Tempier, R., Meadows, G., Vasiliadis, H., Mosier, K., Lesage, A., Stiller, A., Graham, A. \& Lepnurm, M. (2009). Mental disorders and mental health care in Canada and Australia: Comparative epidemiological findings. Social Psychiatry \& Psychiatric Epidemiology, 44(1), 63-72.

Tiffen, R. \& Gittens, R. (2004). How Australia compares. Cambridge: University of Cambridge Press.

valentine, k. (2009) Evidence, values and drug treatment policy. Critical Social Policy, 29(3), 443-464. 
van Beek, I., Dakin, A., Kimber, J. \& Gilmour, S. (2004). The Sydney Medically Supervised Injecting Centre: Reducing harm associated with heroin overdose. Critical Public Health, 14(4), 391-406.

Wodak, A. (2008). Going soft on evidence and due process: Canada adopts US style harm maximization. International Journal of Drug Policy, 19(3), 226-228.

Watson, T. (2014). The politics of harm reduction in federal prisons. International Journal of Drug Policy, 25(5), 916-923.

Yamey, G. (2000). UN condemns Australian plans for 'safe injecting rooms'. British Medical Journal, 320(7236), 667. 